\title{
Relation Between Stress and Lifestyle for Care Workers
}

\author{
Yukiko Kawano $^{1,}$, , Shinichi Demura ${ }^{2}$, Yoshiharu Tanaka ${ }^{3}$, Yoshimasa Matsuura ${ }^{1}$ \\ ${ }^{1}$ Research Organization for University-Community Collaboration, Osaka Prefecture University, Osaka, Japan \\ ${ }^{2}$ Graduate School of Natural Science \& Technology, Kanazawa University, Kanazawa, Ishikawa, Japan \\ ${ }^{3}$ Faculty of Liberal Arts and Sciences, Research Organization for Faculty of Liberal Arts and Sciences, Osaka Prefecture University, Osaka, \\ Japan
}

\section{Email address:}

cyk25481@osakafu-u.ac.jp (Y. Kawano), shinichidemura@d011.dant2.jp (S. Demura), yoshitan@las.osakafu-u.ac.jp (Y. Tanaka), matsuura@las.osakafu-u.ac.jp (Y. Matsuura)

\section{To cite this article:}

Yukiko Kawano, Shinichi Demura, Yoshiharu Tanaka, Yoshimasa Matsuura. Relation Between Stress and Lifestyle for Care Workers. Science Journal of Public Health. Vol. 4, No. 1, 2016, pp. 65-71. doi: 10.11648/j.sjph.20160401.19

\begin{abstract}
This study examined the possible relations between work-related stress and the lifestyle of care workers. A questionnaire regarding occupational stress and lifestyle on care labor was administrated to 507 (119 males and 388 females) care workers. Regardless of a difference in gender, generation, the care environment (care home and home visit), and the employment form (full-time and part-time), many care workers experienced occupational stress. Care workers with more work experience tended to have higher levels of stress than inexperienced workers, and certified care workers had more stress than visiting care for persons with severe disabilities. No relation was observed between stress and lifestyle of the care workers. In conclusion, in the case of care workers, their stress may not be influenced by lifestyle, even if the difference in occupational stress was found through the difference in years of experience and qualifications.
\end{abstract}

Keywords: Care Worker, Stress, Lifestyle, Stress Survey

\section{Introduction}

Although the Health and Welfare Services for the Persons with Disabilities based on Long-term Care Insurance Act (Act No. 123, 1997) and the Services and Supports for Persons with Disabilities Act (Act No. 123, 2005) have been established in Japan, the social need for care services continues to increase. However, the turnover rate for care workers is high, and the labor environment is plagued with issues such as insufficient rest time, low pay, and irregular life rhythm [1-4].

The Care Work Foundation published a survey report [5] on the stress of 1,250 care workers employed at group homes and special unit cares in 2004. According to the report, $85.5 \%$ felt high levels of stress in workplace conditions and labor offices. Specifically, these participants identified four events that induced high stress:

1. Anxiety of increased risk of accidents during the night shift

2. Feeling of being undercompensated for the given job description

3. Difficulty in managing rest time or breaks during work

4. Shortage of care workers
Moreover, in the Care Work Foundation survey [6], the following items were identified as stressful matters for care workers:

1. Shortage of care workers

2. Feeling of being undercompensated for the job description

3. Difficulty in taking paid holidays

4. Great physical burden (risk of back pain and lack of physical fitness)

Zenroren [7] conducted a survey and revealed that care workers have anxieties regarding health, future life, and care-related accidents during working shifts; hence, their work-related anxiety contributed to $90 \%$ of the anxiety in their life in the present and the future. The following measures were taken by the employment management to help relieve the stress of care workers:

1. Training to develop better care ability

2. Training to increase understanding towards dementia

3. Implementing corresponding systems for severe accidents

4. Setting up ways to accept staff requests when scheduling work shifts

In a survey on stress reduction and employment 
management of the care staff in care insurance offices, Hotta [8] reported similar results and indicated that, specifically, the enhancement of employment management contributes to employee stress reduction.

Peiro et al. [9] investigated the stress of care labor in nurses and suggested a positive association between departure intentions and extent of stress. In addition, through their investigation of the stress of caregivers and nurses in care facilities, Cohen [10] and Hare et al. [11] indicated that care staff members work with excessive stress. They suggested improvements to the care labor environment and an increase in the number of care staff members in addition to improvements to the nursing facility environment as a contingency plan. As stated above, the stress of care workers is high and measures to reduce this stressful environment have been proposed. However, significant steps have not been taken to reduce this problem since 2004 .

In general, care labors are differentiated on the basis of years of experience, care environment, employment form, and type and level of care qualifications. Care labors include a wide range of ages: from children with disabilities to the elderly who have dementia or are bedridden; because of this, job descriptions often vary because care receivers are not always the same. This mismatch between care workers' abilities and daily care requirements is considered to be a factor of stress for care workers. On the other hand, studies on the relations between lifestyle and stress and health of general workers reported that women generally have greater stress than men, despite having healthier lifestyles [12]. Furthermore, among female workers, nurses and teachers, in particular, have a great deal of stress.

An investigation of 113 university students revealed that more than $70 \%$ of the students considered their health conditions to be good, but only approximately $40 \%$ of students said that they had little or no stress [13]. In addition, in a related study on work stress and lifestyle of nurses, Nakao [14] reported that work-related stress is caused by mental rather than physical fatigue and that rotational shifts have various effects on the body, in addition to disruption of the body's natural rhythm. Thus, various studies [12-14] have explored stress and lifestyle using samples from nurses, students, and general workers. Although studies [7, 8] on stress and coping with stress have also been conducted for care workers, the relation between stress and lifestyle has not been thoroughly examined. As in the case of general workers, a possibility exists that the stress experienced by care workers also affects their lifestyle.

This study examined the relation between work-related stress and lifestyle of care workers.

\section{Method}

\subsection{Participants}

The participants were care workers belonging to 34 welfare service business offices located in Osaka, Hyogo, Yamaguchi, Chiba and Nagano prefectures. Informed consents from the managers and care workers were obtained after explaining the purpose and content of the experiment in detail. Responses from 507 care workers (119 males and 388 females) were obtained with a collection rate of $97 \%$.

The questionnaire comprised items regarding labor stress, care labor, life circumstances (sleeping duration, breakfast, snacks between meals, frequency of restroom breaks, smoking, and alcohol habits), and general items (including age and gender). This study was approved by the Ethics Committee on Human Experimentation of the Faculty of Human Science, Kanazawa University (Approval No. 2012-20). The participants were aged between 20 and 75 years. Furthermore, to examine the relation between the particular generation and stress, the care workers were divided into five groups: under 30 years ( 87 workers), 30-40 years (127 workers), 40-50 years (111 workers), 50-60 years (113 workers), and over 60 years (69 workers).

Questions on the stress of the labor were answered on a four-point Likert scale: 1 = "strongly feel", 2 = "somewhat feel", 3 = "feel it less" and $4=$ "do not feel it at all". The results indicated that only 10 participants $(2 \%$ overall) gave a rating of 4 . The answer rate for this 'low-stress group', even after including those who answered with 3 's, was $31 \%$. Based on the above results, the following two groups were created: a high-stress group (348 persons, 69\%) who answered with 1's and 2's and a low-stress group (159 persons, 31\%) who answered with 3's and 4's.

\subsection{Care Labor Items}

For care labor items, years of experience, care environment, employment form, and care qualifications were selected as factors. The years of experience factor was divided into five categories: under 1 year, 1-2 years, 1-3 years, 3-5 years, and over 5 years. Care environment was divided into care home and home visit service, and employment form was divided into full-time and part-time. Answers of care qualifications were divided into care manager ( 2 persons), nurse ( 2 persons), assistant nurse ( 3 persons), certified social worker (9 persons), visiting care for persons with severe disabilities (VCPSD) (44 persons), certified care worker (CCW) (184 persons), and home helper (263 persons). To simplify the selection, we placed the following groups in the category of other workers: care manager, nurse, assistant nurse, and certified social worker [2-4].

\subsection{Basic Lifestyle Items}

For questions regarding basic lifestyle, we selected six items: sleep duration, breakfast, snacks between meals, frequency of restroom breaks, smoking, and alcohol use.

For the smoking and sleep duration questions, a two-point scale was used while a four-point scale was used for the other items to answer the frequency per week of these lifestyle items.

The participants chose the following options for sleep duration: 1 = "under eight hours" or 2 = "over eight hours"; breakfast intake: 1 = "everyday," 2 = "sometimes," 3 = 
"hardly eat," and 4 = "not eat at all"; snack between meals: 1 = "everyday," 2 = "sometimes," 3 = "hardly eat," 4 = "not eat at all"; frequency of restroom breaks: 1 = "everyday," $2=$ "sometimes," 3 = "once every two or three days," $4=$ "irregular"; alcohol use: 1 = "everyday," 2 = "sometimes," 3 = "a little," 4 = "not at all." Smoking: 1 = "yes," 2 = "no."

\subsection{Statistical Analysis}

The independence of frequencies among categories was examined using chi-square tests. When significant differences were found, a multiple comparison test was performed. The level of significance was set at 0.05 , which was adjusted using Bonferroni's method.

\section{Results}

Table 1 presents the number, percentage, and test results according to the stress group and low-stress group for gender, generation, years of experience, care environment, employment form, and care qualification of the care workers. Non-significant differences were found among the frequency of stress group and low-stress group for gender, generation, care environment, and employment form. Significant differences were found between frequency of stress group and low-stress group for the years of experience and care qualifications. A multiple comparison test revealed a higher value in the stress group for those aged over five years than those under one year. In the stress group, CCWs (78.3\%) indicated a higher stress rate than VCPSDs (50\%) (Table 1).

Further analyses were performed regarding the years of experience (under one year and over five years) and care qualifications (other workers and VCPSDs).

However, in some cases, very few participants answered with 3's or 4's in the low-stress group (0-3 persons) (for example, for breakfast intake, 3 = "hardly not eat" and $4=$ "not eat at all"). Hence, respondents were split into two groups (for example, for breakfast intake, answers were divided to "eat" or "not eat"). Similarly, other questions were split into two groups, including frequency of restroom breaks ("everyday" or "irregular"), snacks between meals ("do" or "not"), and alcohol use ("drink" or "not").

In addition, the mean sleeping time was $7 \mathrm{~h} 35 \mathrm{~min}(\mathrm{SD}=2$ h $42 \mathrm{~min}$ ), which is similar to the results of a Ministry of Internal Affairs and Communications survey on the fundamental aspects of social life [15], which reported the same to be $7 \mathrm{~h} 42 \mathrm{~min}$. Thus, in this study, persons sleeping over eight hours were classified in the long sleeping group.

Table 2 presents the relations of the lifestyle habits and stress frequency of all care workers.

No significant differences were observed between stress and no-stress groups in all lifestyle habits. Regardless of membership to the stress or low-stress groups, over $80 \%$ of all care workers slept "over eight hours," over $60 \%$ answered "not at all" for snacks between meals, over $60 \%$ answered "everyday" for frequency of restroom breaks, over $50 \%$ answered "not at all" for alcohol use, and over $70 \%$ answered "no" for smoking. However, the low-stress group was more likely not to have the breakfast compared with the stress group.

Table 3 indicates the relations of lifestyle habits and stress frequency between the two groups for care experience (less than one year and over five years). No significant relations were found between the lifestyle habits and stress frequency for either group.

Table 4 indicates relations between lifestyle habits and stress frequency in CCWs and VCPSDs. No significant relations were found between their lifestyle habits and stress frequency.

Table 1. Descriptive statistics for the frequency of stress given different employee characteristics.

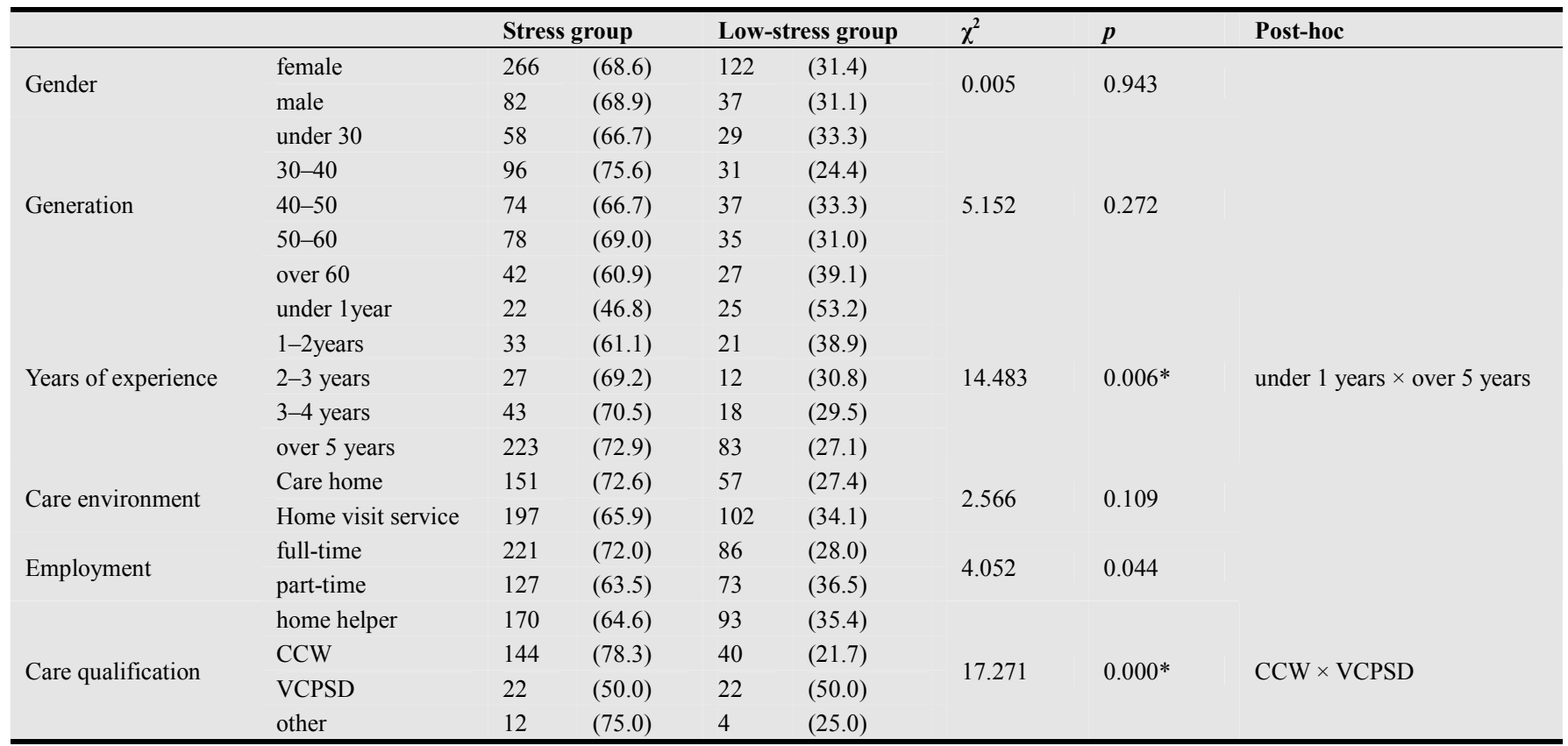

Note. ${ }^{*}: \mathrm{p}<\alpha^{\prime}=0.05 / 6$; VCPSD: Visiting care for persons with severe disabilities; CCW: Certified care worker 
Table 2. Lifestyle habits and stress frequency for all care workers.

\begin{tabular}{|c|c|c|c|c|c|c|c|}
\hline & & \multicolumn{2}{|c|}{ Under 8 hours } & \multicolumn{2}{|c|}{ Over 8 hours } & \multirow{3}{*}{$\frac{\chi^{2}}{0.212}$} & \multirow{3}{*}{$\frac{\mathbf{p}}{0.646}$} \\
\hline \multirow{2}{*}{ Sleeping duration } & Stress group & 283 & $(81.3)$ & 65 & (18.7) & & \\
\hline & Low-stress group & 132 & $(83.0)$ & 27 & $(17.0)$ & & \\
\hline \multirow{4}{*}{ Breakfast } & & Eat & & Not & & \multirow{4}{*}{5.452} & \multirow{4}{*}{0.019} \\
\hline & Stress group & 274 & (78.7) & 74 & (21.3) & & \\
\hline & Low-stress group & 139 & $(87.4)$ & 20 & (12.6) & & \\
\hline & & Eat & & Not & & & \\
\hline \multirow{3}{*}{ Snacks between meals } & Stress group & 124 & $(35.6)$ & 224 & $(64.4)$ & \multirow[t]{3}{*}{0.413} & \multirow[t]{3}{*}{0.521} \\
\hline & Low-stress group & 52 & $(32.7)$ & 107 & $(67.3)$ & & \\
\hline & & Ever & & Irre & & & \\
\hline \multirow[t]{3}{*}{ Frequency of restroom breaks } & Stress group & 233 & $(67.0)$ & 115 & $(33.0)$ & \multirow{3}{*}{0.127} & \multirow{2}{*}{0.721} \\
\hline & Low-stress group & 109 & $(68.6)$ & 50 & (31.4) & & \\
\hline & & Do & & Not & & & \\
\hline \multirow{2}{*}{ Smoking } & Stress group & 88 & (25.3) & 260 & (74.7) & \multirow{2}{*}{0.033} & \multirow{2}{*}{0.855} \\
\hline & Low-stress group & 39 & $(24.5)$ & 120 & $(75.5)$ & & \\
\hline \multirow{3}{*}{ Alcohol use } & & Drin & & Not & & & \\
\hline & Stress group & 172 & $(49.4)$ & 176 & $(50.6)$ & \multirow{2}{*}{1.591} & \multirow{2}{*}{0.207} \\
\hline & Low-stress group & 69 & (43.4) & 90 & (56.6) & & \\
\hline
\end{tabular}

$*: \mathrm{p}<\alpha^{\prime}=0.05 / 6$

Table 3. Lifestyle habits and stress frequency of less than one year and over five years of experience of care.

\begin{tabular}{|c|c|c|c|c|c|c|c|}
\hline & \multicolumn{5}{|c|}{ Sleeping duration } & \multirow{2}{*}{$\chi^{2}$} & \multirow{2}{*}{$\mathbf{p}$} \\
\hline & & Und & Irs & Ove & & & \\
\hline \multirow{2}{*}{ Under 1 year } & Stress group & 19 & $(86.4)$ & 3 & (13.6) & \multirow{2}{*}{0.028} & \multirow{2}{*}{0.867} \\
\hline & Low-stress group & 22 & $(88.0)$ & 3 & $(12.0)$ & & \\
\hline \multirow{2}{*}{ Over 5 years } & Stress group & 183 & $(82.1)$ & 40 & $(17.9)$ & \multirow{2}{*}{0.954} & \multirow{2}{*}{0.329} \\
\hline & Low-stress group & 64 & $(77.1)$ & 19 & $(22.9)$ & & \\
\hline \multirow{4}{*}{ Under 1 year } & & \multicolumn{4}{|c|}{ Breakfast } & & \\
\hline & & \multicolumn{2}{|l|}{ Eat } & \multicolumn{2}{|c|}{ Not eat } & & \\
\hline & Stress group & 17 & $(77.3)$ & 5 & $(22.7)$ & 2002 & 0157 \\
\hline & Low-stress group & 23 & $(92.0)$ & 2 & $(8.0)$ & 2.002 & 0.151 \\
\hline \multirow{3}{*}{ Over 5 years } & Stress group & 182 & $(81.6)$ & 41 & $(18.4)$ & \multirow{2}{*}{2.517} & \multirow{2}{*}{0.113} \\
\hline & Low-stress group & 74 & $(89.2)$ & 9 & $(10.8)$ & & \\
\hline & & \multicolumn{4}{|c|}{ Snacks between meals } & & \\
\hline \multirow{3}{*}{ Under 1 year } & & \multicolumn{2}{|l|}{ Eat } & \multicolumn{2}{|c|}{ Not eat } & \multirow{3}{*}{0.237} & \multirow{3}{*}{0.627} \\
\hline & Stress group & 4 & $(18.2)$ & 18 & (81.8) & & \\
\hline & Low-stress group & 6 & $(24.0)$ & 19 & $(76.0)$ & & \\
\hline \multirow{2}{*}{ Over 5 years } & Stress group & 77 & $(34.5)$ & 146 & $(65.5)$ & \multirow{2}{*}{0.017} & \multirow{2}{*}{0.897} \\
\hline & Low-stress group & 28 & $(33.7)$ & 55 & $(66.3)$ & & \\
\hline & & \multicolumn{4}{|c|}{ Frequency of restroom breaks } & & \\
\hline & & \multicolumn{2}{|c|}{ Everyday } & Irreg & & & \\
\hline Under 1 year & Stress group & 15 & $(68.2)$ & 7 & $(31.8)$ & 0339 & 0560 \\
\hline under l year & Low-stress group & 15 & $(60.0)$ & 10 & $(40.0)$ & 0.359 & 0.500 \\
\hline Over 5 vears & Stress group & 146 & $(65.5)$ & 77 & $(34.5)$ & 0.862 & 0.353 \\
\hline over gouso & Low-stress group & 59 & (71.1) & 24 & $(28.9)$ & & \\
\hline & & Smol & & & & & \\
\hline & & Do & & Not & & & \\
\hline Undor 1 yor & Stress group & 4 & $(18.2)$ & 18 & (81.8) & 0237 & 0627 \\
\hline under I year & Low-stress group & 6 & $(24.0)$ & 19 & $(76.0)$ & 0.231 & 0.021 \\
\hline Over 5 years & Stress group & 50 & $(22.4)$ & 173 & (77.6) & 0096 & 0757 \\
\hline ver s years & Low-stress group & 20 & $(24.1)$ & 63 & (75.9) & 0.090 & 0.121 \\
\hline & & Alco & & & & & \\
\hline & & Drinl & & Not & & & \\
\hline Under 1 year & Stress group & 9 & $(40.9)$ & 13 & $(59.1)$ & 0402 & 0.526 \\
\hline Under l yeal & Low-stress group & 8 & $(32.0)$ & 17 & $(68.0)$ & 0.402 & 0.520 \\
\hline Over 5 vears & Stress group & 106 & $(47.5)$ & 117 & $(52.5)$ & 0212 & 0645 \\
\hline over s years & Low-stress group & 37 & $(44.6)$ & 46 & $(55.4)$ & 0.212 & 0.045 \\
\hline
\end{tabular}


Table 4. Lifestyle habits and stress frequency of CCWs and VCPSDs.

\begin{tabular}{|c|c|c|c|c|c|c|c|}
\hline & & Sleeping d & & & & $x^{2}$ & $n$ \\
\hline & & Under $8 \mathrm{~h}$ & & Over $8 \mathrm{~h}$ & & $x$ & $\mathbf{p}$ \\
\hline \multirow{2}{*}{$\mathrm{CCW}$} & Stress group & 115 & $(79.9)$ & 29 & $(20.1)$ & \multirow{2}{*}{0.537} & \multirow{2}{*}{0.464} \\
\hline & Low-stress group & 34 & $(85.0)$ & 6 & $(15.0)$ & & \\
\hline \multirow{4}{*}{ VCPSD } & Stress group & 19 & $(86.4)$ & 3 & $(13.6)$ & \multirow{3}{*}{0.226} & \multirow{3}{*}{0.635} \\
\hline & Low-stress group & 20 & $(90.9)$ & 2 & $(9.1)$ & & \\
\hline & & Breakfast & & & & & \\
\hline & & Eat & & Not eat & & & \\
\hline \multirow{2}{*}{$\mathrm{CCW}$} & Stress group & 118 & $(81.9)$ & 26 & $(18.1)$ & \multirow{2}{*}{0.007} & \multirow{2}{*}{0.935} \\
\hline & Low-stress group & 33 & $(82.5)$ & 7 & $(17.5)$ & & \\
\hline \multirow{2}{*}{ VCPSD } & Stress group & 18 & $(81.8)$ & 4 & $(18.2)$ & \multirow{2}{*}{0.170} & \multirow{2}{*}{0.680} \\
\hline & Low-stress group & 19 & (86.4) & 3 & (13.6) & & \\
\hline & & \multicolumn{4}{|c|}{ Snacks between meals } & & \\
\hline \multirow{3}{*}{$\mathrm{CCW}$} & & Eat & & Not eat & & \multirow{3}{*}{0.023} & \multirow{3}{*}{0.880} \\
\hline & Stress group & 45 & $(31.3)$ & 99 & $(68.8)$ & & \\
\hline & Low-stress group & 13 & $(32.5)$ & 27 & $(67.5)$ & & \\
\hline \multirow{4}{*}{ VCPSD } & Stress group & 7 & (31.8) & 15 & $(68.2)$ & \multirow{2}{*}{2.071} & \multirow{2}{*}{0.150} \\
\hline & Low-stress group & 3 & (13.6) & 19 & $(86.4)$ & & \\
\hline & & Frequency & room breaks & & & & \\
\hline & & Everyday & & Irregular & & & \\
\hline \multirow{2}{*}{$\mathrm{CCW}$} & Stress group & 92 & $(63.9)$ & 52 & $(36.1)$ & \multirow{2}{*}{0.017} & \multirow{2}{*}{0.897} \\
\hline & Low-stress group & 26 & $(65.0)$ & 14 & $(35.0)$ & & \\
\hline \multirow{4}{*}{ VCPSD } & Stress group & 15 & $(68.2)$ & 7 & $(31.8)$ & \multirow{3}{*}{0.393} & \multirow{3}{*}{0.531} \\
\hline & Low-stress group & 13 & $(59.1)$ & 9 & $(40.9)$ & & \\
\hline & & Smoking & & & & & \\
\hline & & Do & & Not & & & \\
\hline \multirow{2}{*}{$\mathrm{CCW}$} & Stress group & 30 & (20.8) & 114 & $(79.2)$ & \multirow{2}{*}{0.052} & 0820 \\
\hline & Low-stress group & 9 & $(22.5)$ & 31 & $(77.5)$ & & 0.820 \\
\hline VCPSD & Stress group & 4 & $(18.2)$ & 18 & $(81.8)$ & 0.140 & 0.709 \\
\hline VCFDD & Low-stress group & 5 & (22.7) & 17 & (77.3) & 0.140 & 0.109 \\
\hline & & Alcohol & & & & & \\
\hline & & Drink & & Not & & & \\
\hline & Stress group & 61 & (42.4) & 83 & (57.6) & 0.000 & 0.988 \\
\hline cew & Low-stress group & 17 & $(42.5)$ & 23 & $(57.5)$ & 0.000 & 0.900 \\
\hline VCPSD & Stress group & 12 & $(54.5)$ & 10 & $(45.5)$ & 1467 & 0226 \\
\hline VICSD & Low-stress group & 8 & $(36.4)$ & 14 & $(63.6)$ & 1.401 & 0.220 \\
\hline
\end{tabular}

Note. VCPSD: Visiting care for persons with severe disabilities; CCW: Certified care worker

\section{Discussion and Conclusions}

Regardless of differences in gender, generation, care environment (care home and home visit), and employment form (full-time and part-time), many care workers (60-70\%) experienced occupational stress.

According to a survey of the Ministry of Health, Labor and Welfare [16], the rate of persons with daily stress was higher in women than in men, and persons in their $40 \mathrm{~s}$ and $50 \mathrm{~s}$ indicated the highest stress rate. In brief, it was reported that gender and generational differences would be expected for persons with stress. However, in the case of care workers surveyed in this study, high-stress participants did not show gender or generational differences. Therefore, from the present results, it seems that care workers do not attribute their stress to factors such as gender, generation, care environment (care home and home visit), or employment form (full- or part-time).

When comparing groups with different care experiences, those with over five years of experience indicated a higher stress ratio than those with less than one year of experience. According to Nishikawa's [17] report, the number of years in the profession for care workers is generally short, and especially for males, it is shorter than the mean work experience (13.3 years) of general male workers in all industry. The following three reasons are argued to be related to this phenomenon. First, the required knowledge and skills for care labor can be acquired within a short period. Second, there are different types of qualifications and conditions to become a care worker, but they do not receive proportionate raises even during long-term employment. Finally, care insurance offices often do not increase care workers' wages according to their existing qualifications.

Therefore, the incentives of long-term employment provided for care workers by care insurance offices are inadequate. Thus, it follows that their average wage is lower than that of general workers $\left[17^{-} 19\right]$.

In addition, Nishikawa [17] stated that home visiting care workers need three years to obtain a professional level of care skills and presented the following factors regarding the knowledge and necessary skills for the construction and maintenance of adequate relationships with care receivers:

1. Understanding and managing the context related to care

2. Communicating using appropriate language for the care receiver. 
3. Managing and regulating one's own emotions and maintaining professional behaviors

4. Establishing the quality of correspondence during the first meeting

Furthermore, these skills, except for the management of emotions, need more than three years of experience for complete development. Inexperienced care workers may not experience serious stress during the care labor because their primary duties are to obtain the knowledge and skills necessary for establishing communication and relationships with care receivers.

In addition, Yokoyama and Tanaka [20] analyzed the years of experience and gender with a focus on female care managers and reported that of four factors regarding stress-housework burden, marriage child care, salary discrimination, and sexual harassment - the first three are experienced by women with more than one year of experience. Furthermore, they mentioned that inexperienced care workers, despite having lower occupational stress, may experience an increase in stress with increasing opportunities to work with care receivers. This is in-line with this study's results that the care workers with more than five years' of experience may have more stress than inexperienced workers.

In addition, the stress experienced by CCWs was more than that experienced by VCPSDs. Visiting care [21] is the qualification that comprehensively provides care for various everyday-life activities in homes and for outdoors activities, including care for younger persons with severe disabilities. Thus, care workers are able to have mutual understanding with care receivers and a relatively easy time communicating with them $[22,23]$.

On the other hand, certified care [24] is a national qualification required to take care of persons with difficulty in managing daily life due to physical and/or mental disabilities. Both qualifications - certified care and visiting care-deal with different types of care receivers. CCWs focus on a wide range of care and job descriptions, including consultation, advice or social interaction, life support, and physical care.

In addition, because CCWs mainly care for elderly persons with dementia or disabilities, it is difficult for them to obtain mutual understanding in many cases $[25,26]$. For the aforementioned reason, CCWs may feel greater stress than VCPSDs.

No relations were found among stress and lifestyle items (breakfast intake, snacks between meals, frequency of restroom breaks, alcohol use, and sleeping duration) of the care workers. Hence, it is inferred that occupational stress of the care workers is not related with daily lifestyle factors selected in this study.

Because the differences between labor persons with different years of experience (under one year and over five years) and those with different care qualifications (VCPSD and $\mathrm{CCWs}$ ) were found, we examined the relation between stress and lifestyle according to respective groups.

However, no relations were found between stress and lifestyle for either groups with different year of experiences or with different types of care qualifications. Hence, in the case of care workers, their stress may not be influenced by lifestyle, even if the difference in occupational stress was found through the difference in years of experience and qualifications. In the future, examining stressors and the stress-coping abilities of the care workers will be essential to strengthen the relationship between care persons with care receivers.

In conclusion, regardless of differences in gender, generation, care environment (care home and home visit), and employment form (full-time and part-time), many care workers experience occupational stress. Care workers with greater experience have more stress than inexperienced workers, and CCWs have more stress than VCPSDs. No relation was found between stress and lifestyle of the care workers.

\section{Acknowledgments}

This study was mostly supported by the funds of Japan Society for the Promotion of Science Grant-in Aid for Science Research base study (C) for from 2012 to 2014, the furtherance of problem number 24500827.

\section{References}

[1] R. Inaba and M. Inoue, "Relationship between burnout and work-related stress among female nurses with a special scope to occupational career." Japanese Society of Occupational Medicine and Traumatology, vol. 59(3), pp. 129-136, 2011. (in Japanese).

[2] Care Work Foundation, Survey Report for Stress of Care Workers. pp. 1-40, 2005. (in Japanese).

[3] N. Kobiyama, "Care workers' job satisfaction and willingness of turnover. From the point of certified care-worker and service categories." Quarterly of Social Security Research, vol. 45(4), pp. 444-457, 2009. (in Japanese).

[4] K. Tatewaki, "Conceptual framework in dissatisfaction of workers for caring for people in specified homes." Seisen University Articles, vol. 16, pp. 157-176, 2008. (in Japanese).

[5] Care Work Foundation, Survey of Care Workers of Welfare Service Business Offices in 2004. pp. 1-12, 2004. (in Japanese).

[6] Care work Foundation, Survey of Eagerness to Work. Working Conditions and Conditions of Care Workers of Welfare Service Business offices in 2013. pp. 1-11, 2013. (in Japanese).

[7] Zenroren Japan., Reports of Questionnaire on Care Workers and Helpers of Welfare Service Business Offices in 2014. pp. $1-53,2014$. (in Japanese).

[8] S. Hotta, "Survey on stress reduction and employment management of the care staff in the care insurance offices." Quarterly of Social Security Research, vol. 46(2), pp. 150-163, 2010. (in Japanese).

[9] J. M. Peiro, V. González-Romá, and S. Lloret, "Role stress antecedents and consequences in nurses and physicians working in primary health care teams: A causal model." European Review of Applied Psychology, vol. 44(2), pp. 105114, 1994. 
[10] J. Hare and C. P. Clara, "Burnout: differences between professional and paraprofessional nursing staff in acute care and long-term care health facilities." Journal of Applied Gerontology, vol. 7(1), pp. 60-72, 1988.

[11] M. J. Cohen, "Sources of satisfaction and stress in nursing home caregiver: Preliminary results." Journal of Advanced Nursing, vol. 14, pp. 383-388, 1989.

[12] T. Uehata, "General Survey for Stress, Health and Lifestyle [Stress and Health]." Journal of the National Institute of Public Health, vol. 43(3), pp. 385-401, 1993. (in Japanese).

[13] K. Takahashi, A psychological study of relationship between life-style and stress in university students. Hokusho University, vol. 8, pp. 189-200, 2005. (in Japanese)

[14] H. Nakao, T. Kobayashi, and S. Shinagawa, "Relationships between work-related stress: Depression symptoms and lifestyle of nurses." Yamaguchi Prefectural University, vol. 7, pp. 25-31, 2003. (in Japanese).

[15] Ministry of Internal Affairs and Communications, Outline of the 2011 Survey on Time Use and Leisure Activities., pp. 1123,2011 . (in Japanese).

[16] Ministry of Health, Labor and Welfare, Comprehensive Survey of Living Conditions 2008. pp. 1-2, 2011. (in Japanese).

[17] M. Nishikawa, "Real image of care labor." Labor Research, pp. 4-8, 2009. (in Japanese).

[18] A. Yamada and K. Ishii, "Factors for wage determinant and departure intentions in other kinds of jobs and other industries." Quarterly of Social Security Research, vol. 45(3), pp. 229-248, 2009. (in Japanese).
[19] C. Hanaoka, "Huge difference of wage and the departure intentions of the care workers." Quarterly of Social Security Research, vol. 45(3), pp. 269-286, 2009. (in Japanese).

[20] H. Yokoyama and Y. Tanaka, "The study of work-stress of caregivers: The relationship between gender and work-stress." Shimonoseki City University Review, vol. 52(1-2), pp. 67-73, 2008. (in Japanese).

[21] Ministry of Health, Labor and Welfare, Laws of Comprehensive Support for the Daily Life and Social Life of Persons with Disabilities, 2012. (in Japanese).

[22] Ministry of Health, Labor and Welfare, Annual Report of Survey on Actual Situation of Children and Persons with Physical Disabilities, pp. 24-33, 2008. (in Japanese).

[23] Ministry of Land, Infrastructure, Transport and Tourism, Communication Handbook for Persons with Intellectual Disabilities. Mental Disorders and Developmental Disorders. pp. 2-4, 2009. (in Japanese).

[24] Ministry of Health, Labor and Welfare., Overview of Certified Social Worker and Certified Care Worker. Act. 30, 1987. (in Japanese).

[25] T. Taniguchi, J. Takaki, K. Harano, K. Hirokawa, K. Takahashi, E. Fukuoka, Associations between workplace bullying, harassment and stress reactions of professional caregivers at welfare facilities for the elderly in Japan. Sangyo Eiseigaku Zasshi, vol. 54, pp. 1-9, 2012.(in Japanese)

[26] M. Kume, "Communication according to the cause of dementia disease." Japanese Journal of Clinical Deontological Nursing, vol. 20(6), pp. 36-41, 2013. (in Japanese). 